\title{
Optimization of the Internal Roller Burnishing Process for Energy Reduction and Surface Properties
}

\author{
Trung-Thanh Nguyen ${ }^{1}$ - Minh-Thai Le, ${ }^{2}$ * \\ ${ }^{1}$ Le Quy Don Technical University, Faculty of Mechanical Engineering, Vietnam \\ 2 Le Quy Don Technical University, Faculty of Special Equipments, Vietnam
}

Improving the surface quality after burnishing operation has been the subject of various published investigations. Unfortunately, the trade-off analysis between the energy consumption and surface characteristics of the internal burnishing has been not addressed due to the expensive cost and huge efforts required. The objective of the present work is to optimize burnishing factors, including the spindle speed, burnishing feed, depth of penetration, and the number of rollers for minimizing the energy consumed in the burnishing time, as well as surface roughness and maximizing Rockwell hardness. An adaptive neuro-based-fuzzy inference system (ANFIS) was used to develop burnishing objectives in terms of machining parameters. The optimization outcomes were selected using an evolution algorithm, specifically the non-dominated sorting particle swarm optimization (NSPSO). The results of the proposed ANFIS models are significant and can be employed to predict response values in industrial applications. The optimization technique comprising the ANFIS and NOPSO is a powerful approach to model burnishing performances and select optimal parameters as compared to the trial and error method as well as operator experience. Finally, the optimal solution can help to achieve the improvements in the energy consumed by $16.3 \%$, surface roughness by $24.3 \%$, and Rockwell hardness by $4.0 \%$, as compared to the common values

Keywords: roller burnishing; energy reduction; roughness; Rockwell hardness; optimization

Highlights

- Optimizing machining parameters for the internal roller burnishing process of the hardened steel 40X.

- Considering the spindle speed, burnishing feed, burnishing depth, and number of the rollers.

- Evaluating energy consumption, surface roughness, and Rockwell hardness.

- Development of the correlations using ANFIS models.

- Determination of optimal parameters using NSPSO.

\section{INTRODUCTION}

The burnishing operation is an effective solution to boost the surface properties of the machined parts. The outstanding characteristics of the burnished surface, such as reduced roughness, increased hardness, and enhanced compressive stress, can be obtained with the aid of the burnishing process. The optimal factors of different burnishing operations have been selected for improving machining responses. El-Taweel and ElAxir [1] revealed that the burnishing performances, such as the surface roughness and micro-hardness, were primarily affected by the force, feed, speed, and the number of passes, respectively. A roughness of $0.055 \mu \mathrm{m}$ and hardness of $46.69 \mathrm{HRC}$ for the burnished $\mathrm{T} 215 \mathrm{Cr} 12$ material were obtained with the aid of the response surface method [2]. Babu et al. [3] stated that the burnishing depth significantly increased the micro-hardness, while the average roughness was primarily influenced by the burnishing force for the burnishing processes of the EN steels, aluminium alloy, and alpha-beta brass. Tadic et al. [4] emphasized that a small burnishing force significantly contributed to a lower roughness. Cobanoglu and Ozturk [5] indicated that the average roughness and micro-hardness were enhanced by $100.0 \%$ and 55.50 $\%$, as compared to the initial values for the burnished AISI 1040 steel. John and Vinayagam [6] revealed that the optimum values of the roughness and hardness of the burnished Al 63400 were $0.032 \mu \mathrm{m}$ and $91.63 \mathrm{HV}$, respectively.

Revankar et al. [7] presented that the improvements in the surface roughness and microhardness were $77.0 \%$ and $17.0 \%$, as compared to pre-machined properties for the burnished titanium alloy. Amdouni et al. [8] indicated that the burnishing crossed path could be effectively used to decrease the roughness, while the successive one was an alternative solution to increase the hardness for the burnished aluminium alloy. John et al. [9] emphasized that the average roughness could be decreased by $94.5 \%$, and the micro-hardness could be increased by around $41.7 \%$ for the burnishing process of EN-9 alloy. Similarly, the impacts of the processing conditions on the average roughness bore size, and the ovality of the internal roller burnishing were presented by John et al. [10]. The findings revealed that a burnished hole with an acceptable accuracy was produced. Świrad et al. [11] stated that the raster strategy was an effective solution for machining curved paths, while 
the burnishing pressure had a positive impact on the improvement of the burnished surface.

Huuki and Laakso [12] indicated that the compressive stress and average roughness could be improved by $90 \%$ and $400 \%$, while the roundness was enhanced by $38 \%$ for the ultrasonic burnishing of $34 \mathrm{CrNiMo6-M}$ steel. The regression models of the surface roughness and micro-hardness for the ultrasonic-assisted burnishing process of the aluminium alloy were developed by Teimouri et al. [13]. The authors concluded that the proposed approach could bring a higher value of the affected depth. Yang et al. [14] indicated that the cryogenic condition significantly contributed to a decreasing burnishing force and roller wear, enhancing microstructure and hardness, as compared to the dry one for the burnishing of the Co-Cr-Mo biomaterial. Tang [15] agreed that the surface roughness, microstructure, and corrosion resistance of the burnished titanium alloy were improved with cryogenic cooling. Sachin et al. [16] stated that cryogenic burnishing effectively improved surface properties. A new burnishing process was developed to produce the drill shank for minimizing machining costs, resources, and energy [17]. The author stated that the proposed process can replace conventional operations, including heat treatment and grinding. Maximov et al. [18] emphasized that diamond burnishing is an effective approach to enhance the fatigue limits and decrease the surface roughness.

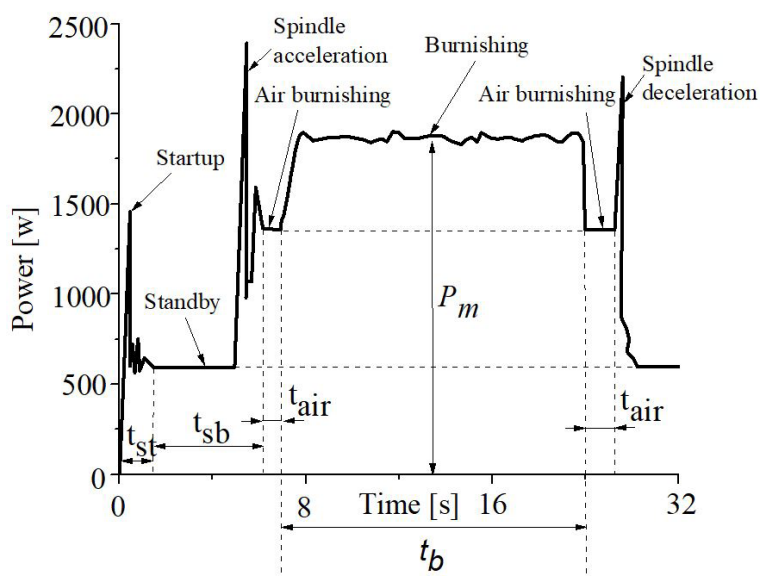

Fig. 1. The power used for the burnishing process

Unfortunately, the influences of machining parameters on the energy consumed for the internal burnishing operation have not been analysed. Furthermore, the relation between the energy reduction and surface properties for the burnishing process has not considered.

\section{METHODS}

\subsection{Optimizing Objectives}

Fig. 1 presents the graph of the power used for the burnishing process. The energy components include the start-up energy $\left(E_{s}\right)$, standby energy $\left(E_{b}\right)$, transition energy $\left(E_{t}\right)$, air-burnishing energy $\left(E_{a}\right)$, and the burnishing energy $\left(E_{b e}\right)$.

The start-up state refers to the shortest period for turning on the machine tool. The standby state presents the stable period, which starts from turning on the machine tool and stops by the spindle rotation. During this time, the lowest amount of energy is consumed. The spindle acceleration/deceleration state refers to the short period for increasing and decreasing the spindle speed. The air-burnishing energy state presents the steady period with spindle rotation but no material burnishing. The burnishing state refers to the steady period for material burnishing.

Practically, the start-up energy, standby energy, transition energy, and air-burnishing energy are less dependent on the variety of machining parameters; hence, the energy consumed in the burnishing state is considered to be an optimization objective. The energy consumed in the burnishing time is calculated as:

$$
E_{b e}=P_{m} \times t_{b},
$$

where $P_{m}$ is the power consumed in the burnishing time; and $t_{b}$ is the burnishing time.

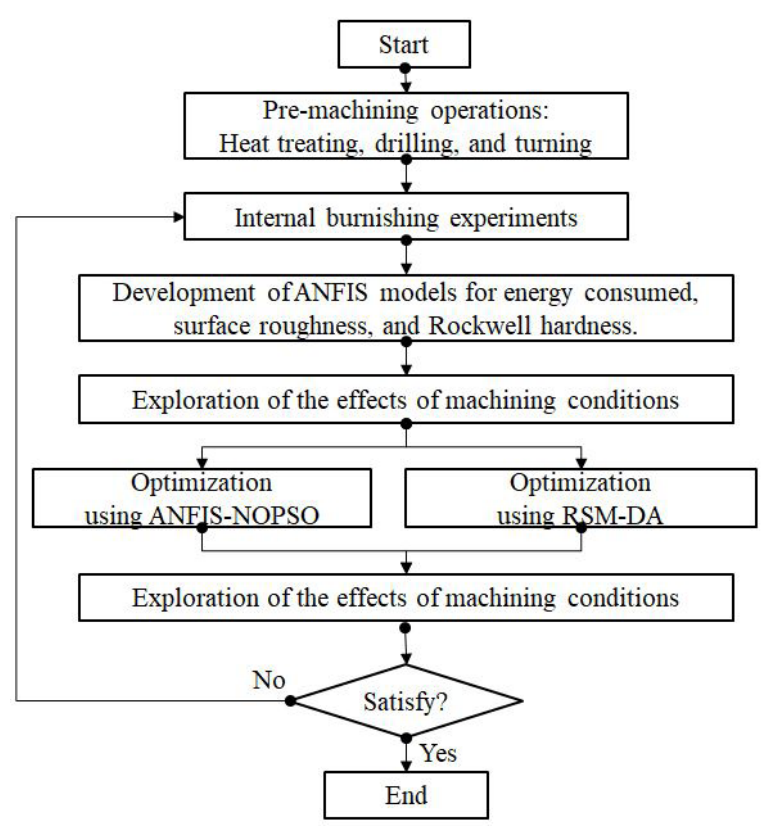

Fig. 2. Optimization approach 
A decreased surface roughness has a significant contribution to the functional performance of mechanical parts and production costs. In the roughness criteria, average roughness $\left(R_{a}\right)$ is considered to be a serious index of the product quality, which indicates the average of the absolute value along the sampling length. Maximum profile peak height $\left(R_{p}\right)$ and Maximum profile valley depth $\left(R_{v}\right)$ are the highest and lowest points along the sampling length, respectively. Practically, a decreased $R_{a}$ leads to a reduction in the $R_{p}$ and $R_{v}$.

The surface roughness $\left(R_{a}\right)$ is calculated as:

$$
R_{a}=\frac{\sum_{i=1}^{5} R_{a i}}{5},
$$

where $R_{a i}$ presents the average roughness at the burnished surface.

The Rockwell hardness $(R H)$ is calculated as:

$$
R H=\frac{\sum_{i=1}^{5} R H_{a i}}{5},
$$

where $R H_{a i}$ is the Rockwell hardness after the burnishing operation at the measured position.

Burnishing factors are presented in Table 1. These ranges are determined based on the characteristics of the burnishing tool, workpiece, and machine tool. These values are verified with the handbooks and aforementioned works.

Table 1. Burnishing parameters

\begin{tabular}{llccc}
\hline Symbol & Parameters & 1 & 2 & 3 \\
\hline$S$ & Spindle speed [rpm] & 1000 & 1500 & 2000 \\
\hline$f$ & Feed rate [mm/min] & 200 & 400 & 600 \\
\hline$D$ & Burnishing depth [mm] & 0.04 & 0.08 & 0.12 \\
\hline$N$ & Number of rollers & 2 & 3 & 4 \\
\hline
\end{tabular}

\subsection{Optimization Procedure}

Fig. 2 presents the optimization approach, which is expressed as follows:

Step 1: The internal burnishing experiments using the Box-Behnken method (BBM) [19]. The BMM is an alternative design of the experimental method, in which a two-level factorial design is combined. Three required levels of each factor are " -1 ", " 0 ", and " 1 ", which presents the low, middle, and high ranges. The design points are placed on the middle points of the edge and the centre of the block. The BBD does not contain parametric combinations at their highest or lowest levels (at the vertices of the cube). This prevents the experiments from being performed under extreme conditions, which may cause unsatisfactory results. In other words, the extreme situations of the responses are avoided. In the BBM, the number of experiments is significantly decreased, which reduces experimental costs.

The number of experiments $(N E)$ in the BoxBehnken method is calculated as:

$$
N E=2 k(k-1)+C_{p},
$$

where $k$ and $C_{p}$ present the number of factors and the number of centre points, respectively.

Step 2: The ANFIS approach describes the impacts of input process parameters on the total energy consumed, surface roughness, and Rockwell hardness. The designed ANFIS model using fivelayer feed-forward neural networks for the burnishing responses is expressed as follows (Fig. 3) [20] and [21]:

Layer 1: In this layer, the membership functions are assigned to the inputs. The outcome of this layer is expressed as:

$$
L A_{1}^{i}=M_{1}^{i}=\mu_{A i(x)} .
$$

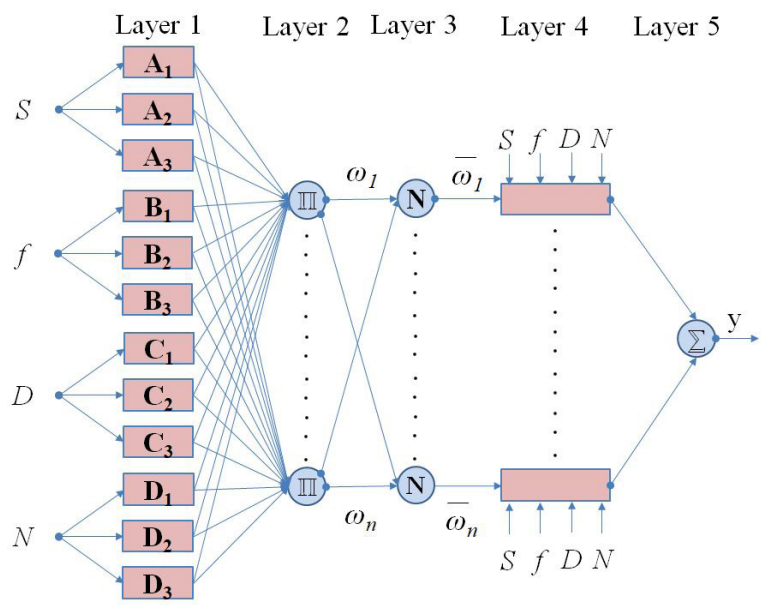

Fig. 3. The typical structure of the ANFIS model

Layer 2: This layer is applied to collect the inputs from the respective fuzzification nodes and determine the firing strength of the rule. The output is expressed as:

$$
L A_{2}^{i}=\omega_{i}=\mu_{A i}(x) \times \mu_{B i}(y) .
$$

Layer 3: This layer is used to determine the ratio of the firing strength of a given rule to the total of firing strengths of all rules. The output is expressed as: 


$$
L A_{3}^{i}=\bar{\omega}_{i}=\frac{\omega_{i}}{\sum_{i=1}^{n} \omega_{i}} .
$$

Layer 4: This layer is employed to defuzzify the received inputs and assign the consequent parameters of the rules. The output is expressed as:

$$
L A_{4}^{i}=\bar{\omega}_{i} y_{i}=\bar{\omega}_{i}\left(a_{i} x+b_{i} x+\mathrm{c}_{i}\right) .
$$

Layer 5: This layer is used to determine the overall output of all incoming signals. The output is expressed as:

$$
L A_{5}^{i}=\sum_{i} \bar{\omega}_{i} f_{i}=\frac{\sum_{i} \omega_{i} f_{i}}{\omega_{i}} .
$$

Step 3: The NOPSO is applied to select optimal factors.

NSPSO is an effective optimization algorithm to improve working efficiency and select non-dominated solutions [22]. Furthermore, NOPSO propels the population towards the Pareto-optimal front. Three niching approaches, including the crowding distance, niche count, and max-min operations, are applied to enhance the diversity of the Pareto front. The principal working of the NOPSO is shown in Fig. 4.

Step 4: The DA is applied to identify optimal values of process parameters and responses, in which each burnishing response is transformed into the function of the desirability (di) [23]. The desirability values are computed for three cases, including the maximum, minimum, and constrained objectives.

Step 5: The comparison of optimal results generated by two optimization approaches is evaluated.

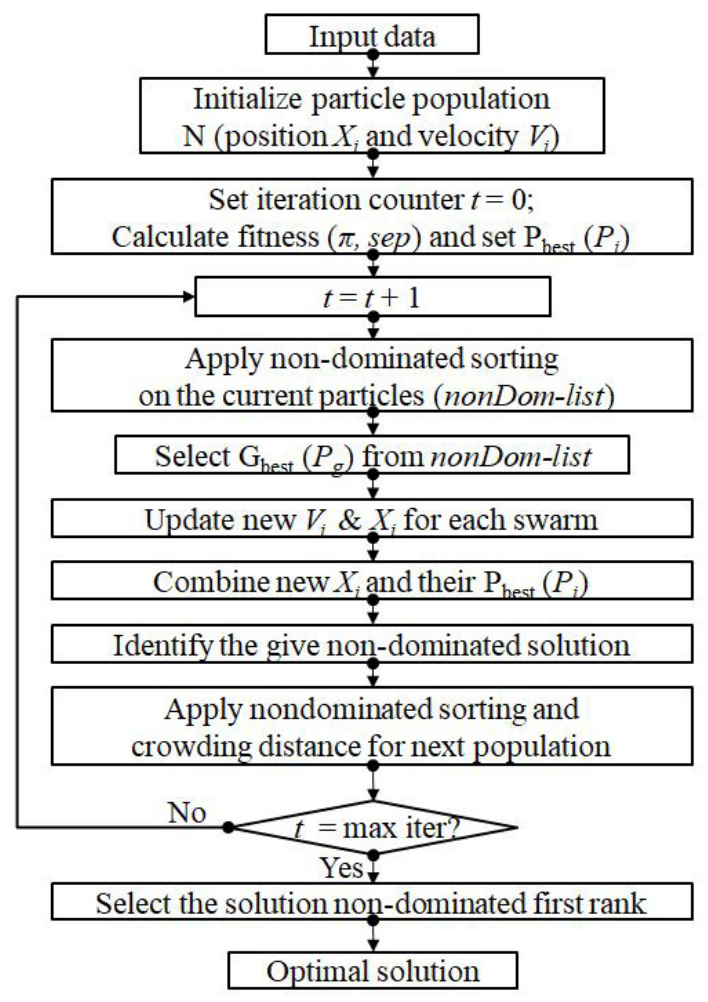

Fig. 4. The principal working of the NOPSO

\section{EXPERIMENTAL}

The round bar of a material labelled $40 \mathrm{X}$ steel is employed to produce machining specimens. The length of $50 \mathrm{~mm}$, the internal diameter of $15 \mathrm{~mm}$, and the diameter of $50 \mathrm{~mm}$ are used for all specimens. The average values of the surface roughness and Rockwell hardness of the pre-machined surface are $2.06 \mu \mathrm{m}$ and 23.2 HRC, respectively. a)

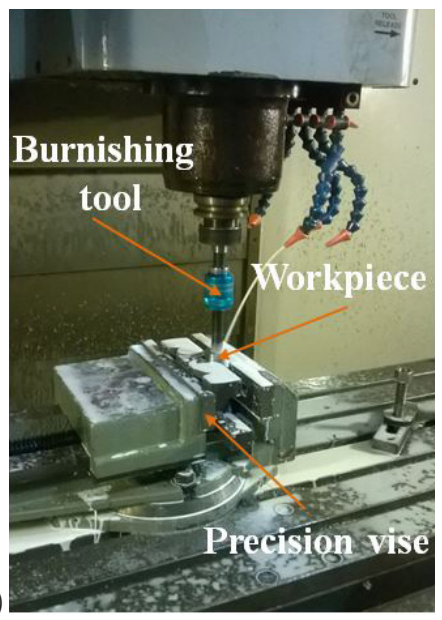

b)

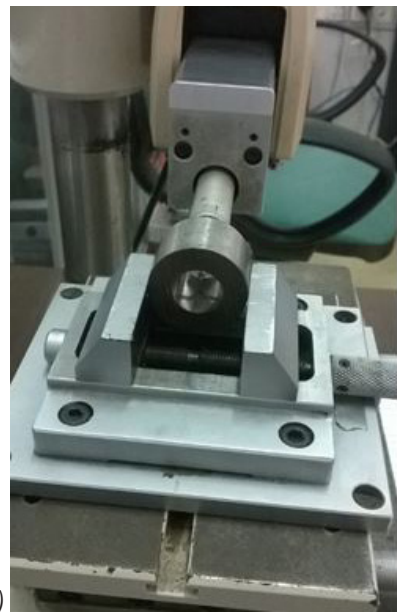

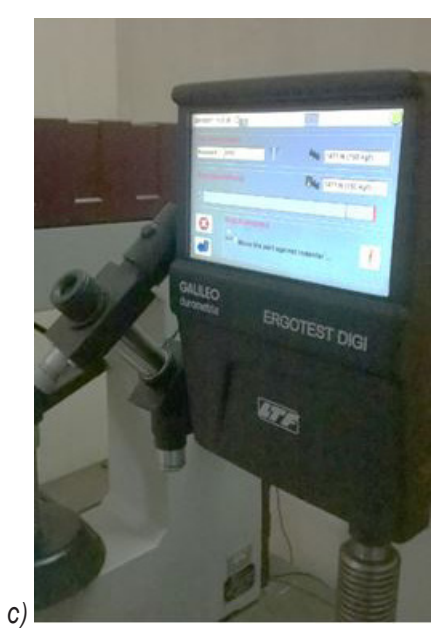

c)

) measuring hardness 
The burnishing trails are done with the support of a CNC milling machine. The burnishing tool is clamped on the machine spindle using the straight shank (Fig. 5a). The linear movement of the burnishing tool is performed with the aid of the Z-axis.

A KEW 6305 power meter is employed to measure power consumption. A reading error of \pm 0.3 $\%$ and full scale error of $\pm 0.2 \%$ are used to enhance the measure accuracy. Moreover, the display update period of 1 second is applied to visualize the capture data. A Mitutoyo SJ-301 tester is used to measure the surface roughness. The length of $4 \mathrm{~mm}$ is measured for each segment (Fig. 5b). The resolution of $0.1 \mu \mathrm{m}$ is employed to improve the accuracy of the measuring data.

A ERGOTEST DIGI-25R tester is used to measure the Rockwell hardness. The pressed load of $150 \mathrm{kf}$ and dwell time of 5 seconds are used for all hardness tests (Fig. 5c). The resolution of 0.1 Rockwell is applied to capture the experimental data.

Table 2. Experimental data for the internal burnishing process

\begin{tabular}{|c|c|c|c|c|c|c|c|c|}
\hline & No. & $S$ [rpm] & $F[\mathrm{~mm} / \mathrm{min}]$ & $D[\mathrm{~mm}]$ & $N$ & $E_{b e}[\mathrm{~kJ}]$ & $R_{a}[\mu \mathrm{m}]$ & $R H[\mathrm{HRC}]$ \\
\hline \multirow{26}{*}{$\begin{array}{l}\text { Experimental data } \\
\text { for developing } \\
\text { ANFIS model }\end{array}$} & 1 & 1000 & 400 & 0.08 & 4.00 & 16.97 & 0.37 & 38.2 \\
\hline & 2 & 2000 & 400 & 0.08 & 2.00 & 18.59 & 0.63 & 37.8 \\
\hline & 3 & 1000 & 400 & 0.08 & 2.00 & 16.08 & 0.39 & 33.5 \\
\hline & 4 & 1500 & 400 & 0.04 & 4.00 & 17.16 & 0.37 & 39.1 \\
\hline & 5 & 1500 & 400 & 0.08 & 3.00 & 17.47 & 0.37 & 42.7 \\
\hline & 6 & 1000 & 600 & 0.08 & 3.00 & 11.73 & 0.58 & 37.1 \\
\hline & 7 & 2000 & 600 & 0.08 & 3.00 & 13.09 & 0.68 & 42.7 \\
\hline & 8 & 1500 & 200 & 0.08 & 2.00 & 32.59 & 0.31 & 34.3 \\
\hline & 9 & 1500 & 400 & 0.08 & 3.00 & 17.49 & 0.36 & 42.4 \\
\hline & 10 & 2000 & 400 & 0.08 & 4.00 & 18.69 & 0.43 & 43.5 \\
\hline & 11 & 2000 & 200 & 0.08 & 3.00 & 35.24 & 0.46 & 37.3 \\
\hline & 12 & 1500 & 600 & 0.12 & 3.00 & 13.01 & 0.52 & 41.0 \\
\hline & 13 & 2000 & 400 & 0.12 & 3.00 & 19.79 & 0.53 & 41.1 \\
\hline & 14 & 1500 & 200 & 0.12 & 3.00 & 34.86 & 0.34 & 36.4 \\
\hline & 15 & 1500 & 400 & 0.04 & 2.00 & 15.91 & 0.47 & 34.7 \\
\hline & 16 & 2000 & 400 & 0.04 & 3.00 & 17.33 & 0.58 & 36.8 \\
\hline & 17 & 1000 & 200 & 0.08 & 3.00 & 31.33 & 0.33 & 32.6 \\
\hline & 18 & 1500 & 200 & 0.08 & 4.00 & 33.56 & 0.21 & 38.7 \\
\hline & 19 & 1500 & 600 & 0.08 & 4.00 & 12.65 & 0.46 & 43.6 \\
\hline & 20 & 1500 & 400 & 0.12 & 2.00 & 18.46 & 0.42 & 39.3 \\
\hline & 21 & 1500 & 400 & 0.12 & 4.00 & 18.53 & 0.32 & 44.1 \\
\hline & 22 & 1000 & 400 & 0.04 & 3.00 & 15.81 & 0.51 & 31.8 \\
\hline & 23 & 1500 & 200 & 0.04 & 3.00 & 30.91 & 0.39 & 33.2 \\
\hline & 24 & 1000 & 400 & 0.12 & 3.00 & 16.99 & 0.46 & 36.2 \\
\hline & 25 & 1500 & 600 & 0.04 & 3.00 & 11.74 & 0.57 & 36.6 \\
\hline & 26 & 1500 & 600 & 0.08 & 2.00 & 12.09 & 0.56 & 39.2 \\
\hline \multirow{13}{*}{$\begin{array}{l}\text { Experimental data } \\
\text { for testing accuracy } \\
\text { of the ANFIS model }\end{array}$} & 27 & 1200 & 200 & 0.06 & 2 & 30.58 & 0.34 & 30.4 \\
\hline & 28 & 1400 & 300 & 0.06 & 2 & 22.47 & 0.37 & 35.2 \\
\hline & 29 & 1600 & 400 & 0.08 & 3 & 17.72 & 0.38 & 42.9 \\
\hline & 30 & 1800 & 500 & 0.08 & 3 & 14.15 & 0.49 & 43.5 \\
\hline & 31 & 1800 & 500 & 0.10 & 4 & 14.64 & 0.37 & 45.6 \\
\hline & 32 & 2000 & 600 & 0.10 & 4 & 13.22 & 0.52 & 44.2 \\
\hline & 33 & 2000 & 600 & 0.12 & 4 & 13.39 & 0.46 & 43.9 \\
\hline & 34 & 1300 & 450 & 0.07 & 3 & 14.64 & 0.41 & 40.7 \\
\hline & 35 & 1700 & 550 & 0.09 & 4 & 13.25 & 0.39 & 45.4 \\
\hline & 36 & 1900 & 550 & 0.11 & 3 & 13.84 & 0.52 & 42.9 \\
\hline & 37 & 1100 & 350 & 0.05 & 3 & 18.64 & 0.42 & 34.6 \\
\hline & 38 & 1700 & 450 & 0.09 & 4 & 16.07 & 0.33 & 45.5 \\
\hline & 39 & 1900 & 550 & 0.05 & 4 & 12.95 & 0.53 & 41.2 \\
\hline
\end{tabular}




\section{RESULTS AND DISCUSSIONS}

\subsection{ANFIS Models for Burnishing Responses}

The experimental data of the internal roller burnishing operation are presented in Table 2. The experimental outcome from 1 to 26 are employed to develop ANFIS models, while the data from 27 to 39 are applied in order to evaluate the precision of the ANFIS correlations.

The 2-2-2-2 structure of the ANFIS model is applied to present the relationship between burnishing parameters and the energy consumed. The 3-3-33 structures of the ANFIS model are used to render the relationships between burnishing parameters and the surface roughness and Rockwell hardness. The membership function labelled gaussmf can bring minimal errors.

The comparisons between the predicted and experimental values of the $E_{b e}, R_{a}$, and $R H$ models are presented in Table 3. The small errors revealed that the ANFIS models can produce acceptable accuracy.

\subsection{ANOVA Results for the Burnishing Responses}

The ANOVA results for the $E_{b e}, R_{a}$, and $R H$ are shown in Tables 4, 5, and 6, respectively. The $R^{2}$ values of the $E_{b e}, R_{a}$, and $R H$ are $0.9883,0.9874$, and 0.9885 , indicating the adequacy of the proposed models.

For the $E_{b e}$ model, the meaningful terms are the single factors $(S, f, D$, and $N)$, interactive factors $(S f$, $S D, f D$, and $D N)$, and the quadratic factor $\left(f^{2}\right)$. The contributions of the $S, f, D$, and $N$ are $5.61 \%, 50.44$ $\%, 5.20 \%$, and $1.56 \%$. The contribution of the $f^{2}$ is
$25.49 \%$. The contributions of the $S f, S D, f D$, and $D N$ are $3.11 \%, 1.57 \%, 3.26 \%$, and $1.43 \%$, respectively.

For the $R_{a}$ model, the meaningful terms are the single factors $(S, f, D$, and $N)$, interactive factors $(S N)$, and quadratic factors $\left(S^{2}, f^{2}\right.$, and $\left.N^{2}\right)$. The contributions of the $S, f, D$, and $N$ are $10.88 \%, 21.59 \%, 14.61 \%$, and $10.07 \%$. The contributions of the $S^{2}, f^{2}$, and $N^{2}$ are $21.59 \%, 8.60 \%$, and $3.65 \%$, respectively. The contribution of the $S N$ is $8.77 \%$.

For the $R H$ model, the meaningful terms are the single factors $(S, f, D$, and $N)$ and quadratic factors $\left(S^{2}, f^{2}, D^{2}\right.$, and $\left.N^{2}\right)$. The contributions of the $S, f, D$, and $N$ are $19.98 \%, 18.78 \%, 16.49 \%$, and $14.70 \%$. The contributions of the $S^{2}, f^{2}, D^{2}$, and $N^{2}$ are $11.77 \%$, $7.31 \%, 9.20 \%$, and $1.09 \%$, respectively.

\subsection{Parametric Influences}

Fig. 6a presents the impacts of the spindle speed and feed rate on the energy consumed. An increment in the feed rate has a significant contribution to a decrement in the burnishing time. The higher the feed rate is, the faster the burnishing will be. Therefore, a higher feed rate causes a reduction in energy consumption. At a higher spindle speed, the momentum of the spindle system increases to satisfy a targeted setting, which causes increased energy consumption. Moreover, an increased spindle speed causes a higher power used of the spindle system, which increases the total power used in the machine tool. The similar influences of the feed rate and spindle speed on the energy consumption for the flat burnishing process were presented in the works of [24] and [25].

Fig. $6 \mathrm{~b}$ presents the influences of the burnishing depth and number of rollers on the energy consumed.

Table 3. Comparative errors for the burnishing responses

\begin{tabular}{cccccccccc}
\hline No. & & $E_{b e}[\mathrm{~kJ}]$ & & & $R_{a}[\mu \mathrm{m}]$ & & $R H[\mathrm{HRC}]$ \\
\hline 27 & Exp. & ANFIS & Err. [\%] & Exp. & ANFIS & Err. [\%] & Exp. & ANFIS & Err. [\%] \\
\hline 28 & 30.58 & 30.14 & 1.44 & 0.34 & 0.33 & 2.94 & 30.4 & 30.8 & 1.30 \\
\hline 29 & 22.47 & 22.78 & 1.38 & 0.37 & 0.38 & 2.63 & 35.2 & 34.7 & 1.42 \\
\hline 30 & 17.72 & 17.56 & 0.90 & 0.38 & 0.36 & 5.26 & 42.9 & 42.1 & 1.86 \\
\hline 31 & 14.15 & 14.47 & 2.26 & 0.49 & 0.48 & 2.04 & 43.5 & 42.9 & 1.38 \\
\hline 32 & 14.64 & 14.42 & 1.50 & 0.37 & 0.36 & 2.70 & 45.6 & 45.2 & 0.88 \\
\hline 33 & 13.22 & 13.44 & 1.64 & 0.52 & 0.53 & 1.89 & 44.2 & 42.8 & 3.17 \\
\hline 34 & 13.39 & 13.63 & 1.79 & 0.46 & 0.45 & 2.17 & 43.9 & 44.5 & 1.35 \\
\hline 35 & 14.64 & 14.49 & 1.02 & 0.41 & 0.43 & 4.65 & 40.7 & 41.5 & 1.93 \\
\hline 36 & 13.25 & 13.48 & 1.74 & 0.39 & 0.38 & 2.56 & 45.4 & 45.9 & 1.10 \\
\hline 37 & 13.84 & 13.62 & 1.59 & 0.52 & 0.51 & 1.92 & 42.9 & 42.4 & 1.17 \\
\hline 38 & 18.64 & 18.35 & 1.56 & 0.42 & 0.41 & 2.38 & 34.6 & 34.1 & 1.45 \\
\hline 39 & 16.07 & 16.33 & 1.62 & 0.33 & 0.32 & 3.03 & 45.5 & 44.9 & 1.32 \\
\hline
\end{tabular}

Exp.: Experimental value; Err.: Error 
Table 4. ANOVA results for the $E_{b e}$ model

\begin{tabular}{lcccc}
\hline So. & $S S$ & $M S$ & $F$ Value & $P$ value \\
\hline Mod. & 1479.343 & 105.667 & 66.370 & $<0.0001$ \\
\hline$S$ & 80.751 & 80.751 & 50.720 & $<0.0001$ \\
\hline$f$ & 726.022 & 726.022 & 456.015 & $<0.0001$ \\
\hline$D$ & 74.796 & 74.796 & 46.979 & $<0.0001$ \\
\hline$N$ & 22.490 & 22.490 & 14.126 & 0.0013 \\
\hline$S f$ & 44.765 & 44.765 & 28.117 & 0.0004 \\
\hline$S D$ & 22.654 & 22.654 & 14.229 & 0.0276 \\
\hline$f D$ & 46.924 & 46.924 & 29.473 & 0.0002 \\
\hline$D N$ & 20.583 & 20.583 & 12.928 & 0.0392 \\
\hline$f^{2}$ & 366.955 & 366.955 & 230.485 & $<0.0001$ \\
\hline Res. & 17.513 & 1.592 & 904.040 & \\
\hline Cor. & 1496.857 & \multicolumn{5}{l}{} \\
\hline Mod.: Model; So.: Source; Res.: Residual; Cor.: Core total
\end{tabular}

Table 5. ANOVA results for the $R_{a}$ model

\begin{tabular}{lcccc}
\hline So. & $S S$ & $M S$ & $F$ Value & $P$ value \\
\hline Mod. & 0.305 & 0.022 & 61.332 & $<0.0001$ \\
\hline$S$ & 0.032 & 0.032 & 90.771 & $<0.0001$ \\
\hline$f$ & 0.064 & 0.064 & 180.181 & $<0.0001$ \\
\hline$D$ & 0.043 & 0.043 & 121.923 & 0.0001 \\
\hline$N$ & 0.030 & 0.030 & 84.036 & $<0.0001$ \\
\hline$S N$ & 0.026 & 0.026 & 73.187 & 0.0225 \\
\hline$S^{2}$ & 0.064 & 0.064 & 180.181 & $<0.0001$ \\
\hline$f^{2}$ & 0.025 & 0.025 & 71.769 & 0.0010 \\
\hline$N^{2}$ & 0.011 & 0.011 & 30.460 & 0.0385 \\
\hline Res. & 0.004 & 0.000 & 834.512 & \\
\hline Cor. & 0.309 & & & \\
\hline
\end{tabular}

Table 6. ANOVA results for the $\mathrm{RH}$ model

\begin{tabular}{lcccc}
\hline So. & SS & MS & F Value & P value \\
\hline Mod. & 318.318 & 22.737 & 67.460 & $<0.0001$ \\
\hline$S$ & 72.521 & 72.521 & 215.166 & $<0.0001$ \\
\hline$f$ & 68.163 & 68.163 & 202.238 & $<0.0001$ \\
\hline$D$ & 59.853 & 59.853 & 177.582 & $<0.0001$ \\
\hline$N$ & 53.341 & 53.341 & 158.260 & $<0.0001$ \\
\hline$S^{2}$ & 42.727 & 42.727 & 126.770 & $<0.0001$ \\
\hline$f^{2}$ & 26.550 & 26.550 & 78.774 & $<0.0001$ \\
\hline$D^{2}$ & 33.401 & 33.401 & 99.100 & $<0.0001$ \\
\hline$N^{2}$ & 3.973 & 3.973 & 11.787 & 0.0056 \\
\hline Res. & 3.708 & 0.337 & 1076.947 & \\
\hline Cor. & 322.025 & & & \\
\hline
\end{tabular}

An increased burnishing depth leads to a higher machining pressure, which causes a greater resistance on the machined surface; hence, higher energy consumed is required to overcome resistance. Similarly, a higher number of rollers causes an increased burnishing pressure. Therefore, more energy is required to burnish the material. The impacts of the burnishing depth and number of rollers on the energy used for the flat burnishing process were similarly described in the works of [24] and [25].

Fig. $7 \mathrm{a}$ presents the influences of the spindle speed and feed rate on the surface roughness. A higher temperature in the machining area is obtained with an increased spindle speed, which causes a reduction in the workpiece hardness. Therefore, the material is easily burnished, and the roughness is reduced. Unfortunately, when the speed increases from 1500 $\mathrm{rpm}$ to $2000 \mathrm{rpm}$, the work-hardening behaviour is appeared, which causes a higher roughness. A higher feed rate causes a higher distance between two consecutive paths; hence, higher roughness is produced. The similar impacts of the feed rate and spindle speed on the surface roughness can be found for the external burnishings [1], [5], [6], and [9], flat burnishings [2], [24], and [25], and the internal burnishings [10], and [17].

Fig. $7 \mathrm{~b}$ presents the influences of the burnishing depth and number of rollers on the surface roughness. Higher burnishing depth causes a larger degree of plastic deformation; hence, low roughness is obtained. A reduction in the roughness with an increased burnishing depth was also found in the published investigations [5], [6], [10], [17], [24], and [25]. A higher number of rollers leads to an increased frequency of engagement; hence, a higher degree of plastic deformation is obtained. More material is burnished, which causes a reduction in the roughness. A similar influence of the number of rollers on the surface roughness was presented in the works of [6], [10], and [25].

Fig. 8a presents the impacts of the spindle speed and feed rate on the Rockwell hardness. A higher feed rate causes an increased burnishing pressure on the machined surface, which increases the degree of the plastic deformation; hence, the Rockwell hardness is improved. A higher spindle speed results in an increased temperature in the burnishing region, which causes an improvement in the larger plastic deformation. More material is then compressed and burnished; hence, the Rockwell hardness is enhanced. A further feed rate and/or speed may cause excessive burnishing temperature, and the residual stress can be relieved; hence, the Rockwell hardness value is decreased. Similar impacts of the spindle speed and feed rate on the machined hardness were presented in the works of [17], [18], [24], [25], and [26].

Fig. $8 \mathrm{~b}$ presents the impacts of the burnishing depth and number of rollers on the Rockwell hardness. An increased burnishing depth results in higher machining pressure, which causes a higher degree 
a)

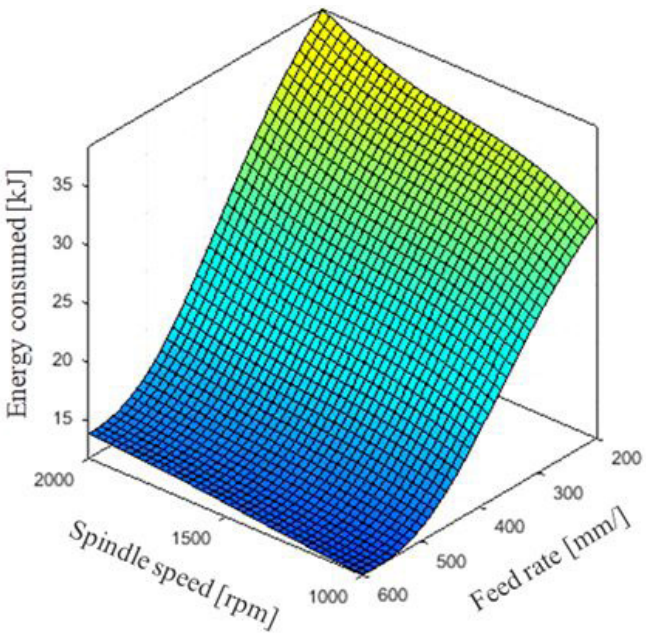

b)

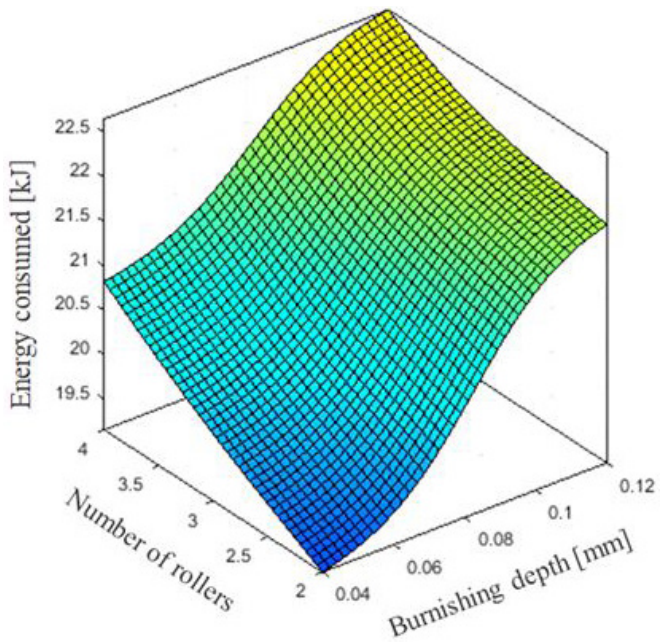

Fig. 6. The influences of the burnishing parameters on the $E_{b}$ : a) $E_{b}$ versus $S$ and f; b) $E_{b}$ versus $D$ and $N$

a)

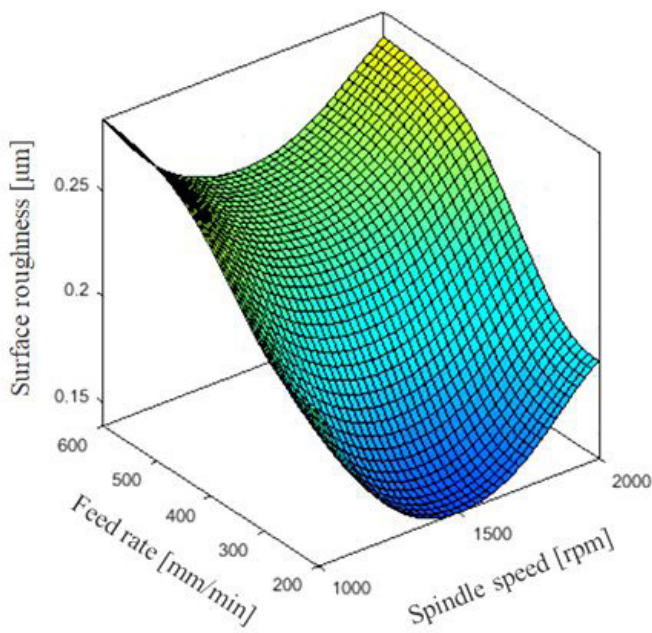

b)

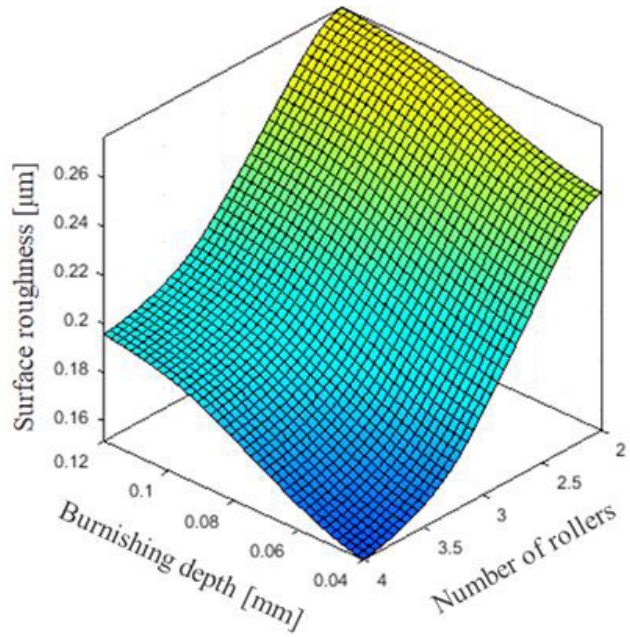

Fig. 7. The influences of the burnishing parameters on the $R_{a}$ : a) $R_{a}$ versus $S$ and $\left.f ; b\right) R_{a}$ versus $D$ and $N$

a)

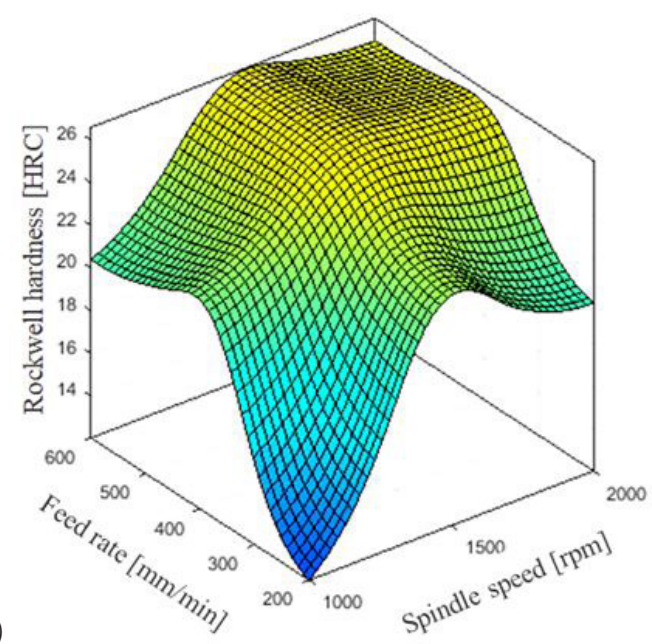

b)

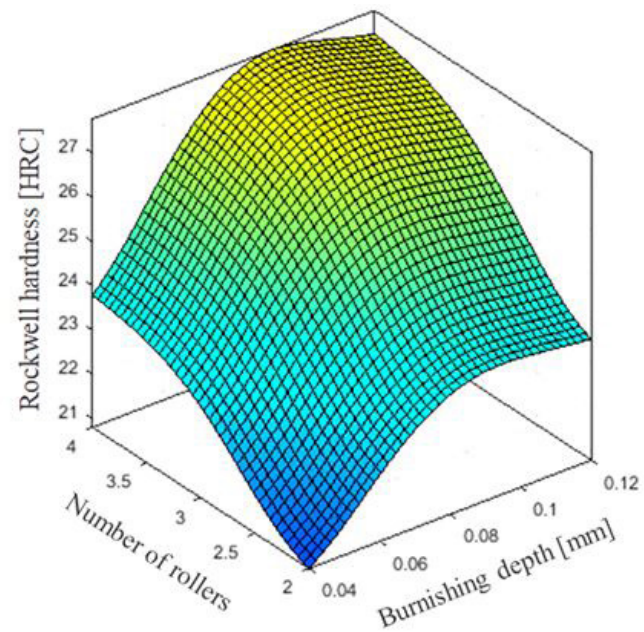

Fig. 8. The influences of the burnishing parameters on the $R H$ : a) $R H$ versus $S$ and $f$; b) $R H$ versus $D$ and $N$ 
of work-hardening; hence, the Rockwell hardness is enhanced. However, a further burnishing depth leads to higher burnishing temperature and the residual stress can be relieved; hence, the Rockwell hardness is decreased. As the number of rollers increases, more material is compressed and burnished. A higher degree of plastic deformation is generated; hence, higher Rockwell hardness is obtained. An increased hardness with higher burnishing depth and the number of rollers can be found in the works of [17], [18], [24], [25], and [26].

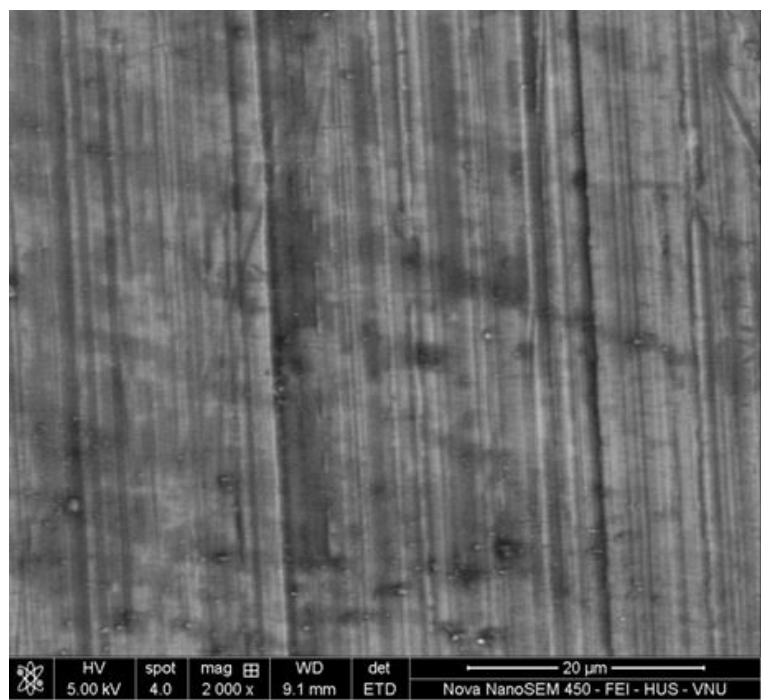

Fig. 9. Surface morphology after burnishing process

The surface morphology after the burnishing operation is presented in Fig. 9 with the aid of a Nano Nova 450"scanning electron microscope. It can be stated that a smooth surface can be achieved using the burnishing process. The pre-machined defects, such as grooves, cracks, and waviness, were filled.

\subsection{Optimization Outcomes Generated by NOPSO}

The single optimization is executed to find the best outcome for each response, as shown in Table 7.

The Pareto graphs produced by NSPSO are shown in Fig. 10. The global relation between the energy consumption and average roughness is depicted in Fig. $10 \mathrm{a}$, while the trade-off analysis between the energy consumption and Rockwell hardness is presented in Fig. 10b.

It can be stated that machining performances have contradictory trends. The minimization of the average roughness may lead to increased energy consumed and decreased Rockwell hardness. Three typical solutions, including points 1,2 , and 3 , are chosen to evaluate the burnishing performances (Table 8).

For the first point, the average roughness increases, while the energy consumed and Rockwell hardness decreases; hence, this solution does not satisfy the optimization requirement. For the second point, the energy consumed increases, while the average roughness and Rockwell hardness decrease; hence, this point cannot consider as a proper solution. For the third solution, the energy consumed and average roughness simultaneously are decreased, while the Rockwell hardness increases, as compared to the initial values. Consequently, the third point can be selected as an appropriate solution to enhance burnishing performances.

Based on the optimization requirement, the third point is selected as the optimal point. As a result, the optimum values of the spindle speed, feed rate, burnishing depth, and the number of rollers are 1513 $\mathrm{rpm}, 490 \mathrm{~mm} / \mathrm{min}, 0.11 \mathrm{~mm}$, and 4, respectively. The reductions in $E_{b e}$ and $R_{a}$ are $16.3 \%$ and $24.3 \%$,

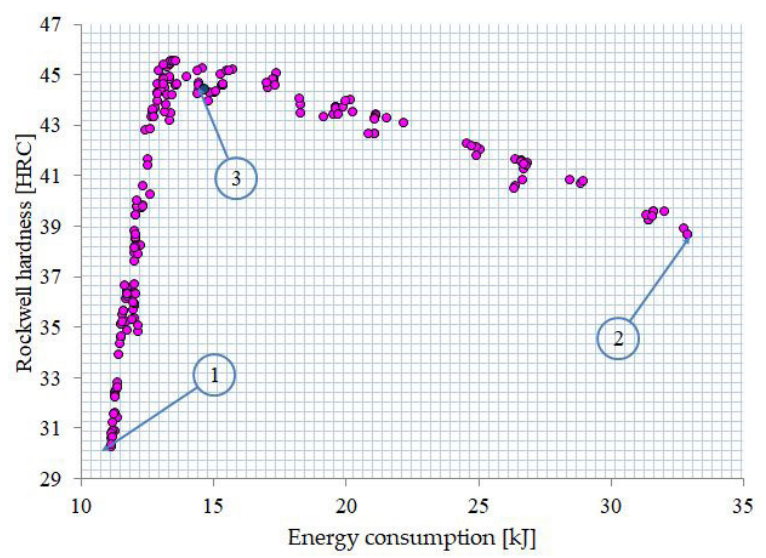

a)

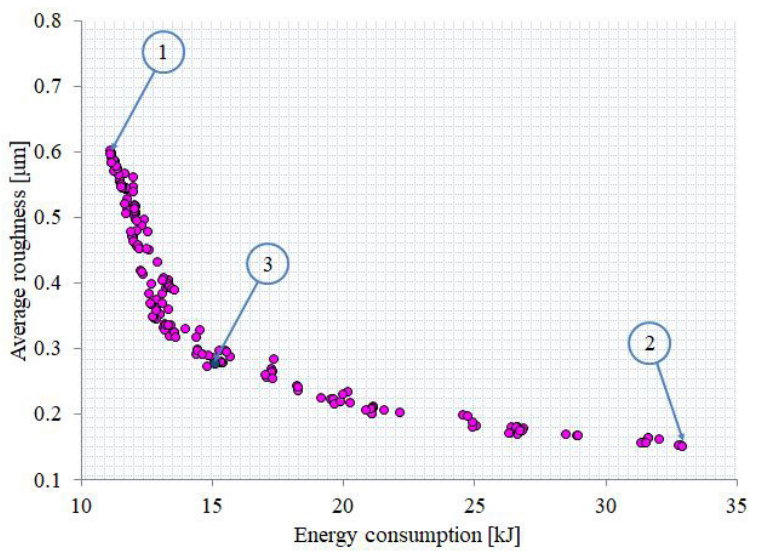

b)

Fig. 10. Pareto graphs: a) $E_{b}$ versus $R_{a}$; b) $E_{b}$ versus $R H$ 
Table 7. Optimization results for each response

\begin{tabular}{|c|c|c|c|c|c|c|c|}
\hline \multirow{2}{*}{ Scenarios } & \multicolumn{4}{|c|}{ Optimization parameters } & \multicolumn{3}{|c|}{ Responses } \\
\hline & $S$ [rpm] & $f[\mathrm{~mm} / \mathrm{min}]$ & $D[\mathrm{~mm}]$ & $N$ & $E_{b e}[\mathrm{~kJ}]$ & $R_{a}[\mu \mathrm{m}]$ & $R H[\mathrm{HRC}]$ \\
\hline For minimizing Eb & 1000 & 600 & 0.04 & 2 & 11.09 & & \\
\hline For minimizing $\mathrm{Ra}$ & 1484 & 200 & 0.12 & 4 & & 0.16 & \\
\hline For maximizing $\mathrm{RH}$ & 1545 & 480 & 0.10 & 4 & & & 45.6 \\
\hline
\end{tabular}

Table 8. Optimization results for the burnishing responses using ANFIS-NOPSO

\begin{tabular}{lccccccc}
\hline Method & \multicolumn{3}{c}{ Optimization parameters } & \multicolumn{4}{c}{ Responses } \\
\cline { 2 - 9 } & $S[\mathrm{rpm}]$ & $f[\mathrm{~mm} / \mathrm{min}]$ & $D[\mathrm{~mm}]$ & $N$ & $E_{b e}[\mathrm{~kJ}]$ & $R_{a}[\mu \mathrm{m}]$ & $R H[\mathrm{HRC}]$ \\
\hline Initial values & 1500 & 400 & 0.08 & 3 & 17.47 & 0.37 & 42.7 \\
\hline Point 1 & 1024 & 573 & 0.04 & 2 & 11.16 & 0.60 & 29.5 \\
\hline Point 2 & 1470 & 224 & 0.12 & 4 & 32.23 & 0.17 & 39.1 \\
\hline Point 3 & 1513 & 490 & 0.11 & 4 & 14.63 & 0.28 & 44.4 \\
\hline Improvement [\%] & & & & & -16.3 & -24.3 & 4.0 \\
\hline
\end{tabular}

respectively, while the $R H$ is enhanced by $4.0 \%$, as compared to the initial values.

\subsection{Optimization Outcomes Generated by DA}

The mathematical models of the $E_{b e}, R_{a}$, and $R H$ are expressed using Eqs. (10) to (12), respectively.

$$
\begin{aligned}
E_{b e}= & 44.70623+0.00374 S-0.13858 f+63.7 D \\
& +1.47729 N-0.000006 S f+0.01614 S D \\
& -0.08356 f D-7.35 D N+0.00013 f^{2}, \\
R_{a}= & 0.78458-0.00088 S-0.00013 f-1.75 D \\
& +0.19583 N-0.00009 S N+0.0000004 S^{2} \\
& +0.000001 f^{2}-0.01875 N^{2},
\end{aligned}
$$

$$
\begin{aligned}
R H & =-33.99167+0.04038 S+0.05858 f \\
& +316.39167 D+6.68633 N-0.000012 S^{2} \\
& -0.000065 f^{2}-1773.41146 D^{2}-0.88208 N^{2}
\end{aligned}
$$

Optimization outcomes are shown in Fig. 11. The optimum values of the spindle speed, feed rate, burnishing depth, and the number of rollers are 1427 $\mathrm{rpm}, 468 \mathrm{~mm} / \mathrm{min}, 0.09 \mathrm{~mm}$, and 4, respectively. The reductions in the $E_{b e}$ and $R_{a}$ are $14.4 \%$ and $2.7 \%$, respectively, while the $R H$ is enhanced by $2.8 \%$, as compared to the initial values.

\subsection{Evaluation of Optimization Outcomes}

As given in Table 8, the ANFIS-NOPSO provides the improvements in the $E_{b e}, R_{a}$, and $R H$ are $16.3 \%, 24.3$
$\%$, and $4.0 \%$, respectively. As shown in Table 9 , the reductions in the $E_{b e}$ and $R_{a}$ are $14.4 \%$ and $2.7 \%$, respectively, while the $R H$ is enhanced by $2.8 \%$ at the optimal solution produced by the RSM-DA. It can be stated that the ANFIS-NOPSO is more efficient than the RSM-DA regarding the optimization issues for the burnishing operation.

\subsection{Scientific and Industrial Contributions}

The optimal values of process parameters and burnishing responses are only determined using the optimization technique. The ANFIS-NOPSO is more efficient than the RSM-DA in resolving the complex optimizing issue.

The proposed optimization approach using ANFIS and NOPSO can be applied to solve optimization problems for different burnishing operations with different materials.

The scientific findings can be effectively applied in future works for optimization of the burnishing operation or development of the expert system in terms of the burnishing process.

The ANFIS models of the energy consumed, surface roughness, and Rockwell hardness have been developed in terms of machining factors. These models have an industrial interest, which can be applied to forecast the burnishing performances for hardened 40X steel.

The optimal outcomes generated by the ANFISNOPSO can be employed to improve the technical parameters for the internal burnishing operation of hardened 40X steel. 
Table 9. Optimization results for the burnishing responses using RSM-DA

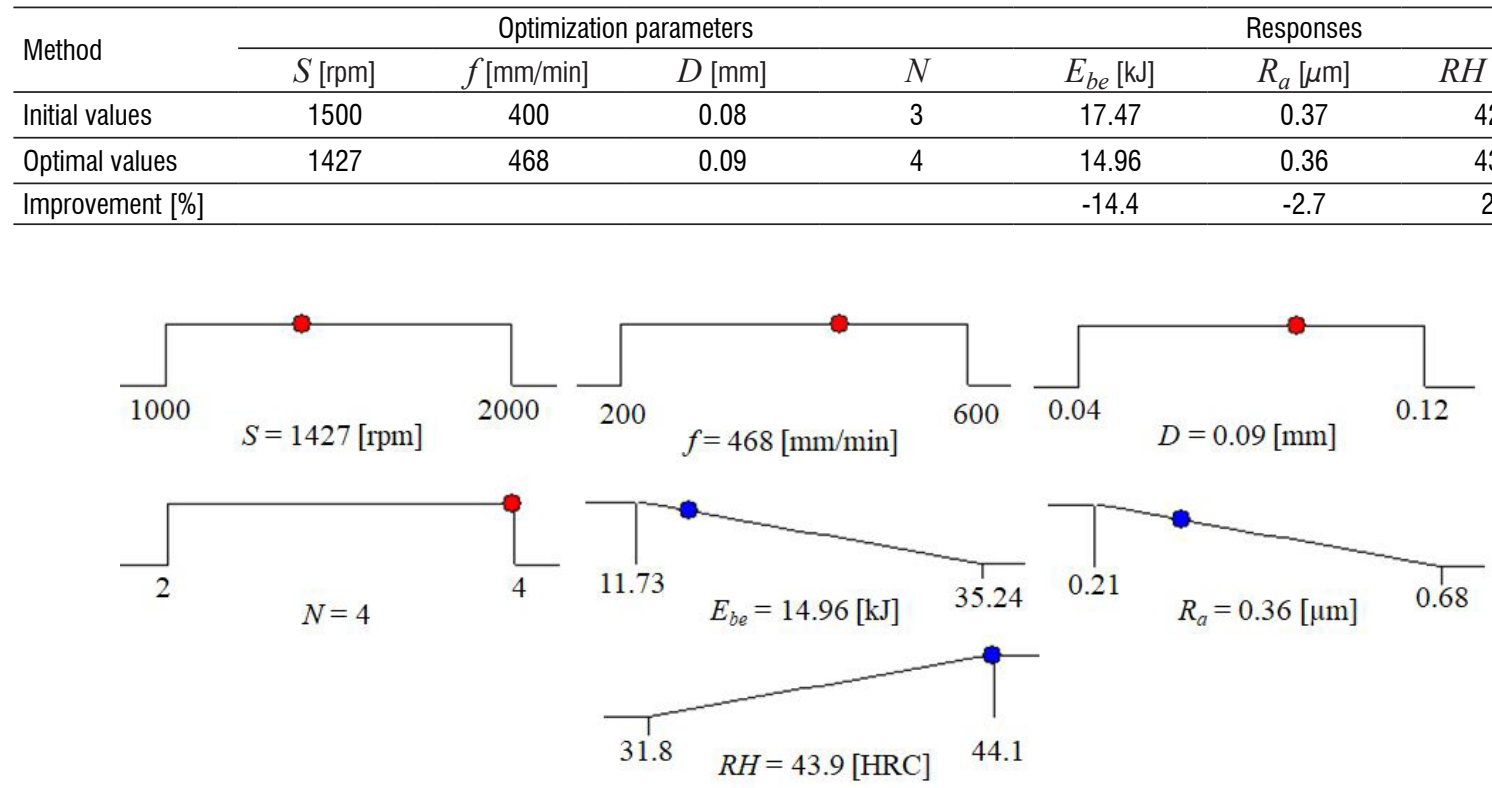

Fig. 11. The optimal values generated by the DA

Moreover, the parametric influences can help machine operators deeply understand the impacts of burnishing factors on the process responses.

\section{CONCLUSIONS}

In this investigation, an attempt has been made to optimize the machining conditions of the roller burnishing operation for reducing the energy consumed in the burnishing state, surface roughness, and Rockwell hardness. The inputs considered are the spindle speed, burnishing feed, burnishing depth, and the number of rollers. The ANFIS method was employed to propose the predictive models of technical outcomes. The NSPSO was utilized to find optimal outcomes. The conclusion can be presented as bellows:

1. The minimum values of the spindle speed, burnishing depth, and the number of rollers can be applied to save the energy consumed, while the highest feed rate is recommended to apply. Higher values of the burnishing depth and number of rollers can be employed to decrease the roughness, while a minimum feed rate leads to a reduction in the roughness. The middle level of the spindle speed is used to obtain a smooth surface. Higher levels of process parameters are recommended to enhance the Rockwell hardness.
2. The ANFIS models of the energy consumption in the burnishing time, surface roughness, and Rockwell hardness can be applied to predict the response values with high accuracy. These developed models are effectively employed to save experimental costs and human efforts.

3. The Pareto fronts can significantly help machine operators to determine proper parameters for decreasing energy consumed as well as average roughness and enhancing Rockwell hardness. The appropriate selection of process parameters can decrease machining costs, time, operator skills, and efforts.

4. As shown in the optimal setting generated by NSPSO, the optimal parameters of the $S, f, D$, and $N$ are $1513 \mathrm{rpm}, 490 \mathrm{~mm} / \mathrm{min}, 0.11 \mathrm{~mm}$, and 4 , respectively. The $E_{b e}$, and $R_{a}$ are decreased by $16.3 \%$ and $24.3 \%$, while the $R H$ is enhanced by $4.0 \%$, respectively in comparison with the initial values.

5. In the current investigation, the machining factors are optimized to decrease the energy consumption as well as average roughness and to improve the Rockwell hardness. Practically, the impacts of burnishing parameters on the residual stress, the depth of the affected layer, and machining costs have been not presented. Therefore, a holistic optimization considering 
more burnishing performances will be addressed in future investigation.

\section{ACKNOWLEDGEMENTS}

This research is funded by Vietnam National Foundation for Science and Technology Development (NAFOSTED) under grant number 107.04-2020.02.

\section{NOMENCLATURE}

$D \quad$ Burnishing depth, [mm]

$E_{b e}$ Energy consumption in the burnishing time, [kJ]

$f \quad$ Feed rate, $[\mathrm{mm} / \mathrm{min}]$

$M S$ Mean square

$N \quad$ Number of rollers

$R H$ Rockwell hardness, [HRC]

$S \quad$ Spindle speed, [rpm]

SS Sum of squares

$R_{a}$ Surface roughness, $[\mu \mathrm{m}]$

\section{REFERENCES}

[1] El-Taweel, T.A., El-Axir, M.H. (2009). Analysis and optimization of the ball burnishing process through the Taguchi technique. The International Journal of Advanced Manufacturing Technology, vol. 41, p. 301-310, D0l:10.1007/s00170-0081485-6.

[2] Stalin John, M.R., Vinayagam, B.K. (2011). Optimization of ball burnishing process on tool steel (T215Cr12) in CNC machining centre using response surface methodology. Arabian Journal for Science and Engineering, vol. 36, p. 1407-1422, DOI:10.1007/s13369-011-0126-9.

[3] Babu, P.R., Ankamma, K., Prasad, T.S., Raju, A.V.S., Eswara Prasad, N. (2012). Optimization of burnishing parameters and determination of select surface characteristics in engineering materials. Sadhana, vol. 37, p. 503-520, D0l:10.1007/ s12046-012-0092-2.

[4] Tadic, B., Todorovic, P.M., Luzanin, O., Miljanic, D., Jeremic, B.M., Bogdanovic, B., Vukelic, D., (2013). Using specially designed high-stiffness burnishing tool to achieve highquality surface finish. International Journal of Advanced Manufacturing Technology, vol. 67, p. 601-611, D0l:10.1007/ s00170-012-4508-2.

[5] Cobanoglu, T., Ozturk, S. (2014). Effect of burnishing parameters on the surface quality and hardness. Proceedings of the Institution of Mechanical Engineers, Part B: Journal of Engineering Manufacture, vol. 229, no. 2, p. 286-294, DOI:10.1177/0954405414527962.

[6] Stalin John, M.R., Vinayagam, B.K. (2014). Optimization of nonlinear characteristics of ball burnishing process using Sugeno fuzzy neural system. Journal of the Brazilian Society of Mechanical Sciences and Engineering, vol. 36, p. 101-109, Dol:10.1007/s40430-013-0060-8.

[7] Revankar, G.D., Shetty, R., Rao, S.S., Gaitonde, V.N. (2014). Analysis of surface roughness and hardness in ball burnishing of titanium alloy. Measurement, vol. 58, p. 256-268, D0l:10.1016/j.measurement.2014.08.043.

[8] Amdouni, H., Bouzaiene, H., Montagne, A., Van Gorp, A., Coorevits, T., Nasri, M., lost, A. (2017). Experimental study of a six new ball-burnishing strategies effects on the Al-alloy flat surfaces integrity enhancement. International Journal of Advanced Manufacturing Technology, vol. 90, p. 2271-2282, DOI:10.1007/s00170-016-9529-9.

[9] Stalin John, M.R., Banerjee, N., Shrivastava, K., Vinayagam, B.K., (2017). Optimization of roller burnishing process on EN-9 grade alloy steel using response surface methodology. Journal of the Brazilian Society of Mechanical Sciences and Engineering, vol. 39, p. 3089-3101, Dol:10.1007/s40430. 016-0674-8.

[10] Stalin John, M.R., Balaji, B., Vinayagam, B.K., (2017). Optimisation of internal roller burnishing process in CNC machining center using response surface methodology. Journal of the Brazilian Society of Mechanical Sciences and Engineering, vol. 39, p. 4045-4057, Dol:10.1007/s40430. 017-0871-0.

[11] Świrad, S., Wydrzynski, D., Nieslony, P., Krolczyk, G.M. (2019). Influence of hydrostatic burnishing strategy on the surface topography of martensitic steel. Measurement, vol. 138, p. 590-601, D0I:10.1016/J.measurement.2019.02.081.

[12] Huuki, J., Laakso, S.V.A. (2012). Integrity of surfaces finished with ultrasonic burnishing. Proceedings of the Institution of Mechanical Engineers, Part B: Journal of Engineering Manufacture, vol. 227, no. 1, p. 45-53, Dol:10.1177/0954405412462805.

[13] Teimouri, R., Amini, S., Bami, A.B. (2018). Evaluation of optimized surface properties and residual stress in ultrasonic assisted ball burnishing of AA6061-T6. Measurement, vol. 116, p. 129-139, Dol:10.1016/j.measurement.2017.11.001.

[14] Yang, S., Umbrello, D., Dillon, O.D.Jr., Puleo, D.A., Jawahir, I.S. (2015). Cryogenic cooling effect on surface and subsurface microstructural modifications in burnishing of $\mathrm{Co}-\mathrm{Cr}-\mathrm{Mo}$ biomaterial. Journal of Materials Processing Technology, vol. 217, p. 211-221, D0I:10.1016/j.jmatprotec.2014.11.004.

[15] Tang, J., Luo, H.Y., Zhang, Y.B. (2017). Enhancing the surface integrity and corrosion resistance of Ti-6Al-4V titanium alloy through cryogenic burnishing. International Journal of Advanced Manufacturing Technology, vol, 88, p. 2785-2793, DOI:10.1007/s00170-016-9000-y.

[16] Sachin, B., Narendranath, S., Chakradhar, D. (2019). Enhancement of surface integrity by cryogenic diamond burnishing toward the improved functional performance of the components. Journal of the Brazilian Society of Mechanical Sciences and Engineering, vol. 41, art. ID 396, D0I:10.1007/ s40430-019-1918-1.

[17] Tajane, R.S., Pawar, P.J. (2020) Investigation into burnishing to minimize heat treatment in drill manufacturing. Materials and Manufacturing Processes, vol. 35, no. 7, p, 817-825, D0l:10.1 080/10426914.2020.1743848.

[18] Maximov, J.T, Duncheva, G.V., Anchev, A.P., Dunchev, V.P. (2020). Smoothing, deep, or mixed diamond burnishing of low-alloy steel components - optimization procedures. International Journal of Advanced Manufacturing Technology, vol. 106,p. 1917-1929, DOl:10.1007/s00170-019-04747-2. 
[19] Nguyen, T.-T., Mia, M., Dang, X.-P., Le, C.-H., Packianather, M.S. (2020). Green machining for the dry milling process of stainless steel 304. Proceedings of the Institution of Mechanical Engineers, Part B: Journal of Engineering Manufacture, vol. 234, no. 5, p. 881-899, Dol:10.1177/0954405419888126.

[20] Hegedüs, F., Bécsi, T., Aradi, S., Gáspár, P. (2019). Motion planning for highly automated road vehicles with a hybrid approach using nonlinear optimization and artificial neural networks. Strojniški vestnik - Journal of Mechanical Engineering, vol. 65, no. 3, p. 148-160, D0I:10.5545/svjme.2018.5802.

[21] Ghritlahre, H.K., Prasad, R.K. (2018). Exergetic performance prediction of a roughened solar air heater using artificial neural network. Strojniški vestnik - Journal of Mechanical Engineering, vol. 64, no.3, p. 194-206, D0l:10.5545/svjme.2017.4575.

[22] Wang, Y., Liu, Z., Cai, L., Cheng, Q., Dong, X. (2018). Optimization of oil pads on a hydrostatic turntable for supporting energy conservation based on particle swarm optimization. Strojniški vestnik - Journal of Mechanical
Engineering, vol. 64, no. 2, p. 95-104, D0l:10.5545/svjme.2017.4742.

[23] Nguyen, T.-T., Vu, T.-C., Duong, Q.-D. (2020) Multi-responses optimization of finishing honing process for surface quality and production rate. Journal of the Brazilian Society of Mechanical Sciences and Engineering, vol. 42, art. ID 604, D0l:10.1007/ s40430-020-02690-y.

[24] Nguyen, T.-T., Cao, L. H., Dang, X. P., Nguyen, T.-A., Trinh, Q. $H$. (2019). Multi-objective optimization of the flat burnishing process for energy efficiency and surface characteristics. Materials and Manufacturing Processes, vol. 34, 1888-1901, DOI:10.1080/10426914.2019.1689266.

[25] Nguyen, T.-T., Cao, L.-H., Nguyen, T.-A., Dang, X.-P. (2019). Multiresponse optimization of the roller burnishing process in terms of energy consumption and product quality. Journal of Cleaner Production, vol. 245, D0l:10.1016/j.jclepro.2019.119328.

[26] Nguyen, T.T., Mia, M. (2020). Modeling and evaluation of energy efficiency of new hybrid turning-burnishing process in terms of surface properties. Energies, vol. 13, no. 18, art. ID 4929, DOI:10.3390/en13184929. 